\title{
THE TEACHING OF HISTORY OF SCIENCE AT THE UNIVERSITY: SOME BRIEF CONSIDERATIONS
}

\author{
Paolo Bussotti \\ University of Udine, Italy
}

I teach history of science at the University of Udine, Italy. My students - about 25 - frequently the second and the third year at the faculty of Letters and Philosophy (now called "Polo Umanistico"). They have to pass a sole proof in history of science. Therefore, in this editorial, I would like to face the problems connected with the teaching of history of science to students who have a scarce knowledge of mathematics and who in their future will have probably few contacts with science and its history. Thus, two problems are particularly difficult in this case: 1 ) to choose the subject properly; 2) to choose the appropriate educational approach. Obviously, the choice of the subject is always important, but if one teaches history of science in a scientific faculty, the situation is, in a sense, easier: for example, at the faculty of physics, one could select a specific course each year, i.e., history of mechanics in a certain period, history of electromagnetism in the $19^{\text {th }}$ century, the theory of optics as it is developed by an author or a series of authors (Euclid, Witelo, Kepler, Snell, Descartes, and so on), etc. Each subject could be dealt with by facing the particular research of each scholar and entering the specific mathematical arguments. This is not possible in a humanities faculty. Thence, I would like to explain my choice and to trace some general considerations.

\section{The Subject}

As a subject, I have chosen history of astronomy. This choice has been conceived because of a precise reason: astronomy has been the first science to assume a well codified and precise form. The Greek astronomy, in the final form offered by Ptolemy (about 100-170 AD), is a discipline, which, given the specification of the initial hypotheses, the precision of the deductive chains, the appropriate use of mathematics and observations is a perfect model for the students to understand which some of the main features of science are. Furthermore, in Ptolemy's epoch, mathematical astronomy had already a long history, dating at least to Eudoxus (408-355 BC). After the Greek period, astronomy continued to be an interesting subject to understand the way in which the Arabic civilization preserved the Greek culture and to realize till what extent the Arabic astronomers were original. The "rebirth" of astronomy in Western Europe around the beginning of the XIV century, till reaching Copernicus, represents an ideal perspective point to catch some of the aspects connoting the development of European culture in the late middle ages-beginning of the modern age. The discussions on the validity and the status of the Copernican system until Kepler's Astronomia Nova (1609), Galilei's Sidereus Nuncius (1610) and censure of Copernicanism (1616) (my course arrives at that date) are profound subjects to realize the conceptual core of how a scientific theory can be developed as well as the connections science-society. Therefore, I am convinced that history of astronomy is a particularly suitable subject for a history of science course conceived for students who have historical and philosophical interests, which go beyond science. It is a perfect, an ideal subject due to the long and the stratified history of astronomy. The other subjects are less appropriate to offer such a picture. These are the conceptual reasons why I suggest to dedicate to astronomy the proof of history of science in a humanities faculty. In the next section, more specific educative-didactical reasons will be offered.

To be more precise, my educational itinerary has been conceived like this:

1) Distinctions of the apparent motions connoting the different celestial bodies: i) so called fixed stars; ii) Sun; iii) Moon; iv) planets;

2) Astronomical reference-frames: horizontal, equatorial, ecliptic (used didactical support: Romano, pp. 19-36); 
3) Most important relations between these systems: the succession of the seasons (Romano, pp. 2730);

4) The solar theory of Hipparchus-Ptolemy, focusing in particular on the geometrical models (Evans, pp. 208-216)

5) Importance of Hipparchus (about 190-120 BC) as an astronomer;

6) Epistemological considerations: the different astronomical models: i) kinematical models; ii) physicalcosmological models; iii) dynamical models; iv) models which are both physical and dynamical (for the specification of this term, see Bussotti, 2015).

7) Precession of the equinoxes as an astronomical phenomenon (Romano, pp. 61-64)

8) Hipparchus' work on the fixed stars: i) the classification of the stars according to Hipparchus; ii) a hint to the modern classification of the stars;

9) Hipparchus' theory of the apparent motions of the so called fixed stars;

10) Hipparchus and Ptolemy: determination of the longitudes of the fixed stars (Evans, pp. 247-254);

11) Problems connected with the theory of precession;

12) Planets: the fundamental positions of the planets with respect to the Earth in modern astronomy; i) inferior planets: the elongations, superior and inferior conjunctions. The "first" and the "second" anomaly: the retrograde motion; ii) the superior planets: conjunctions, oppositions, the two anomalies, explanation of the retrograde motion;

13) Sidereal and synodic periods;

14) Planets: Apollonius-Ptolemy planetary theory, with particular reference to the retrograde motions both for inferior and superior planets (Evans, pp. 337-342);

15) Ptolemy's equant;

16) A hint to the status of astronomy in Western Europe during the early middle ages;

17) A hint to the Arabic astronomy and its connection with Greek astronomy. The role of the Arabs in the conservation of the Greek culture;

18) The "rebirth" of astronomy in the Western Europe from the XIII to the XVI century: a hint of John Holywood; Roger Bacon; Gherardo da Cremona; Nicholas of Cusa; Georg von Peuerbach; Johannes Müller.

19) The cultural milieu in which Copernicus (1473-1543) was educated, lived and worked;

20) The Commentariolus: the content of the work and the heliocentric system;

21) Letter against Werner;

22) The content of the De Revolutionibus Orbium Coelestium with a rapid examination of the subjects dealt with in each chapter of the six books composing the work;

23) Specific and profound examination of: a) preface by Osiander; b) Copernicus' letter to the Pope Paolo III; c) the initial eleven chapters of the first book of the De Revolutionibus focusing, in particular, on the motions Copernicus ascribed to Earth's axis.

24) Status of the Copernican and Ptolemaic theory after Copernicus;

25) The proofs proposed by Kepler (1571-1630) in his Mysterium Cosmographicum (1596) in favour of the Copernican theory: strong and weak points of such proofs;

26) A hint to Kepler's Astronomia Nova (1609): the main narrative and conceptual features of such work. The first two planetary laws and the attempt to construct a physical astronomy;

27) Galilei's (1564-1642) Sidereus Nuncius (1610) specific examination: a) the structure of the moon as seen by Galilei with the telescope; b) the composition of the Milky Way; c) Jupiter's satellites;

28) The role of the Sidereus Nuncius within the discussion on the Copernicanism;

29) The censure of the Copernicanism (1616).

\section{The Educational Approach}

One of my principal aims was to offer a good knowledge of the main features characterising some important aspects of positional astronomy, this is the reason why I dealt with the different astronomical reference frames. With regard to the way in which the lectures properly concerning the history of astronomy were conceived, I followed the same approach: first of all, the students have to learn the technical aspects of Ptolemy's and Copernicus' theories. Most part of the course has been, hence, developed in the attempt to clarify and to specify the techniques used by the scientist whose works have been faced during the lectures. Obviously, there was a big problem: most of 
the students did not have a sufficient knowledge of the mathematics used by Ptolemy and Copernicus. It was not thinkable to offer all the necessary mathematical elements because my entire course was 40 hours long. Thence, I have chosen this approach: I have prepared a long series of slides (about 190). By far most of them were dedicated to the technical aspects. I referred to the geometric figures and I tried to explain as many technical particulars as possible, reducing mathematics to measure the angles and first degree equations and identities. I basically used a visual approach. I present here four slides (translated from Italian into English) concerning Apollonius' model for the planetary motion and for the retrogradation of the inferior planets to give an idea how the slides have been conceived:

\section{Apollonius' Model (1)}

- The figure is imagined as belonging to the plane of the Ecliptic. The centre of the deferent is the Earth. The point $K$ moves with a constant speed eastwards. The motion of $K$ is called mean motion of the planet. It would represent the true motion of the planet if the speed-anomaly and the retrogradation did not exist. The period of $K$ is the sidereal period of the planet - for the external planets - and it is a year for Mercury and Venus. Why? (Let us think that the inferior planets have limited elongations) [question posed to the students during the lecture].

$\checkmark \underline{\lambda}$ is defined as umean longitude of the planet»

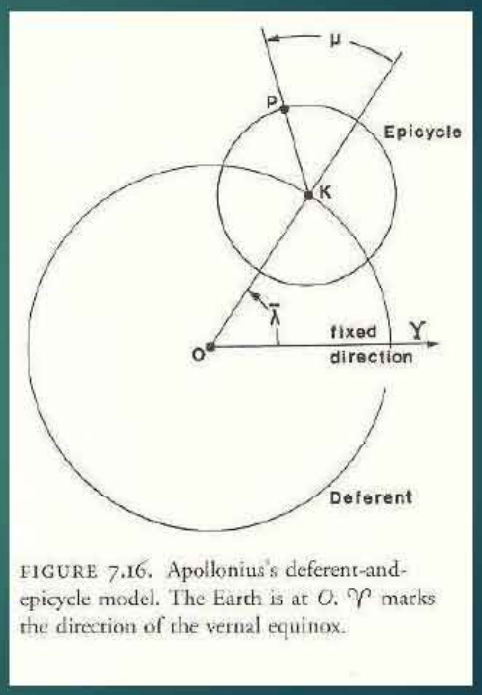

\section{Apollonius' Model (2)}

The planet $P$ rotates on the epicycle with a constant speed. The position of the planet on the epicycle is defined by the epicyclic anomaly $\mu$. The planet completes a revolution on the epicycle in its synodic period.

This is the general model. Let us see the details to explain the retrogradations.

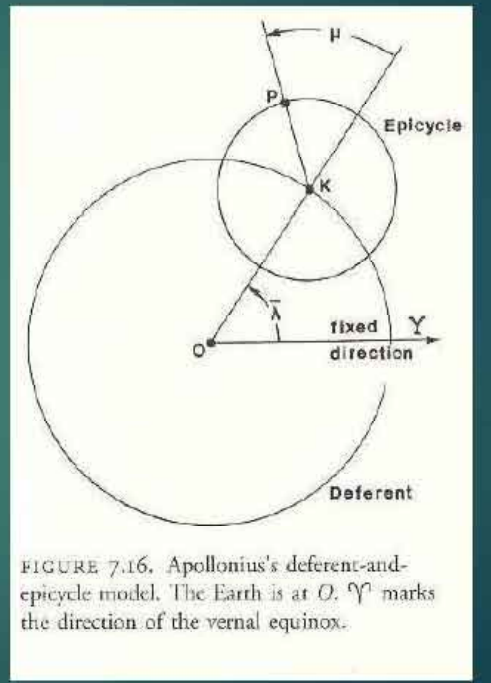



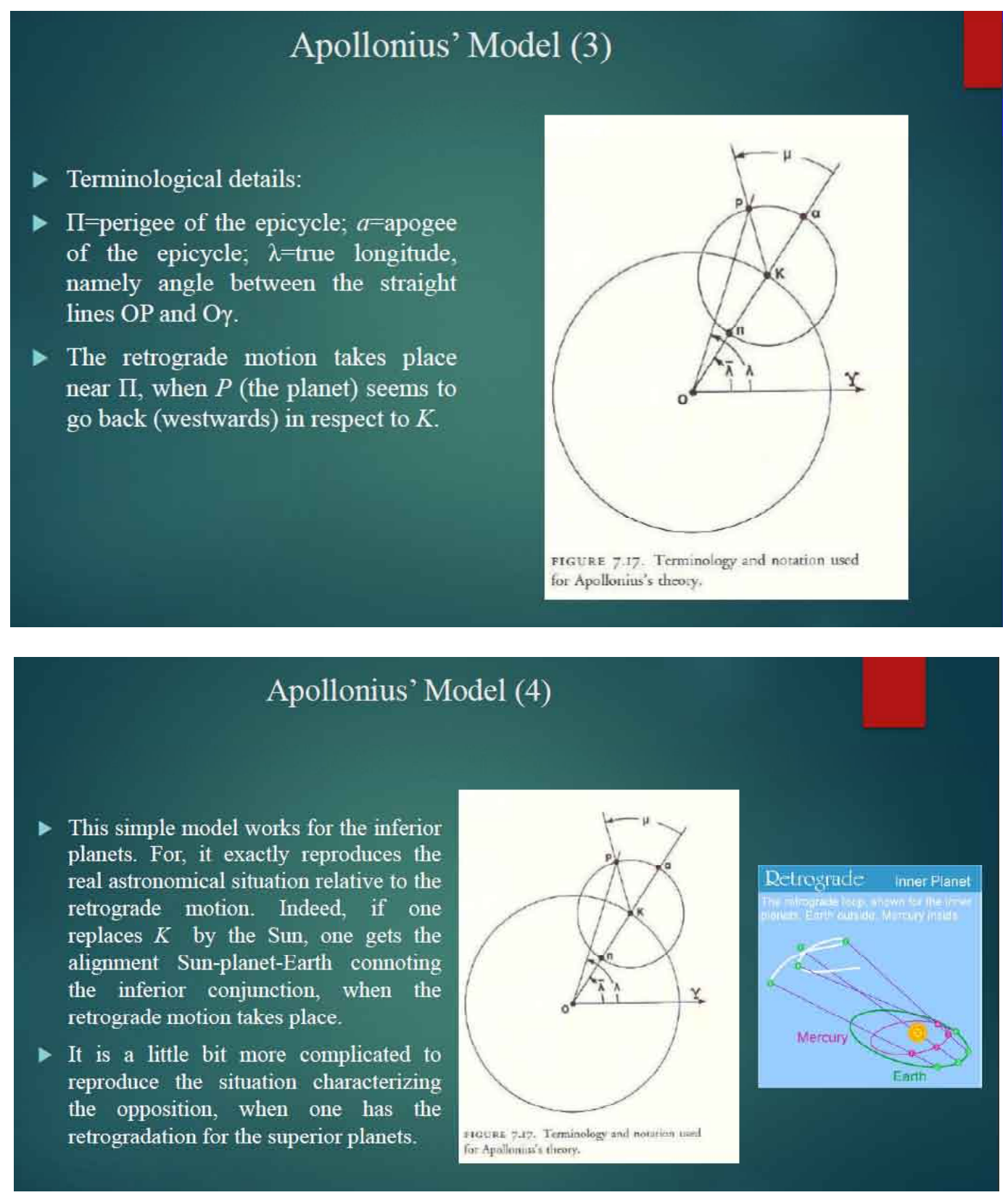

I have commented on and explained each single slide. By means of this approach, the students have reached a satisfactory level of knowledge of the techniques and concepts used in astronomy in the Greek period and by Copernicus. Clearly: if I could have used a little bit of mathematics more, the knowledge of the students would have been more profound, but this was not possible. Hence, I consider the result obtained by this method a positive one. Only after that the students caught the technical details of astronomy I have spoken of historiographical and epistemological problems as well as of the relations science-society. For, I am convinced, it is unacceptable to speak of things which are not known. I think, for example, it is erroneous to speak of Ptolemaic astronomy or Copernican revolutions without knowing, at least, the main specific technical features of these theories.

The principal material for the proof the students have to pass is given by the slides I have prepared. They have also: 1) to study the astronomical reference-systems in a good and elementary handbook as Romano (see references); 2) to integrate my slides with Evan's book as far as the conceptions of the Greek astronomers are referred 
to; 3 ) to study the preface of Osiander, Copernicus' letter to the Pope Paolo III and the first eleven chapters in the first book of Copernicus' De Revolutionibus; 4) Galilei's Sidereus Nuncius.

\section{References}

Bussotti, P. (2015). The complex itinerary of Leibniz Planetary Theory. Physical Convictions, Metaphysical Principles and Keplerian Inspiration. Basel: Birkhäuser.

Copernicus, N. (1979). Opere. Torino [UTET]. This volume contains the Italian translation of the Commentariolus, letter against Werner and De Revolutionibus Orbium Coelestium (I have used in the lectures).

Evans, J. (1998). The history and practice of ancient astronomy. New York - Oxford: Oxford University Press.

Galilei, G. (1610). Sidereus Nuncius. Venedig: Baglioni. An English translation is freely available at http://homepages.wmich. edu/ mcgrew/Siderius.pdf.

Romano, G. (1993). Introduzione all'astronomia. Esercitazioni e problemi per lo studio dei fenomeni celesti [An introduction to astronomy. Exercises and problems for the study of the celestial phenomena]. Padova: Muzzio.

Received: October 15, 2015

Accepted: October 25, 2015

Paolo Bussotti

Ph.D., Researcher, University of Udine, via Palladio 8, 33100 Udine, Italy. E-mail: paolobussotti66@gmail.com

Website: http://www.scienzainrete.it/documenti/autori/paolo-bussotti 